\title{
The impact of whole multidisciplinary team experience transfer on the launch of a new Cystic Fibrosis Centre
}

\author{
Katarzyna Walicka-Serzysko, Justyna Milczewska, Dorota Sands \\ Cystic Fibrosis Department, Institute of Mother and Child, Warsaw, Poland \\ Cystic Fibrosis Centre, Paediatric Hospital, Dziekanow Lesny, Poland
}

\section{ABSTRACT}

\begin{abstract}
Introduction: Survival rates and quality of life among patients with cystic fibrosis $(\mathrm{CF})$ can be attributed to a holistic approach to disease management. A joint approach to healthcare, facilitated by a multidisciplinary team (MDT) that subscribes to continuing professional development, can ensure better service delivery. The launch of a new state-of-the-art centre in Warsaw provided an opportunity to facilitate departure training for an entire multidisciplinary team by sharing practices with an experienced CF centre in Dresden, Germany. The primary objective was to assess the change in MDT comfort levels in providing CF care after participating in CF-specific training.

Material and methods: Assessments were performed before opening a new CF centre, to inform the development of an 18-hour curriculum tailored to the complexity of CF care. Providers experienced in CF care $(n=15)$, and new workers $(n=11)$ participated in the training. Pre- and post-course surveys assessed the MDT's comfort with the three targeted domains of CF care (involvement in CF care, knowledge of CF management, and practical skills in CF care) using a five-point Likert scale.

Results: Among course participants $(n=26)$, there was a statistically significant difference in the questionnaire results before and after training in total $(p=0.000)$ as well as for the three categories (involvement $[p=0.000]$, knowledge $[p=0.000]$, and skills $[p=0.000]$ ). The average overall pre-training score was 86.6 , which varied from an average of \pm 26.8 (SD) to $112.1 \pm 15.4$ (SD) after training.

Conclusions: A joint approach (MDT) to CF care, with the aim of disseminating best practices, increased awareness as to what constitutes best practice. Participants reported increased levels of comfort in administering CF care. There was clear willingness to participate in continuing professional development and self-assessment. The study confirmed the need for a more robust approach to CF MDT care training, particularly among new employees.
\end{abstract}

\section{KEY WORDS:}

cystic fibrosis, multidisciplinary team, education.

\section{INTRODUCTION}

Cystic fibrosis (CF) is a systemic disease that requires comprehensive treatment and a coordinated approach. Over the last decade, CF care has improved worldwide in line with the European Cystic Fibrosis Society (ECFS) standards [1]. The quality of care and life expectancy has increased significantly as a result $[2,3]$. In fact, CF has ceased to be a disease confined to paediatrics, with over $50 \%$ of the living population over the age of 18 years.

The catalysts for change include early diagnosis through neonatal screening, new treatments, and clinical research. Furthermore, the significance of national and international registers in providing data for epidemiolog-

\section{ADDRESS FOR CORRESPONDENCE:}

Katarzyna Walicka-Serzysko, Cystic Fibrosis Department, Institute of Mother and Child, 17A Kasprzaka St., 01-211 Warsaw, Poland, e-mail: katwalicka@imid.med.pl 
ical study cannot be understated [1-3]. Fundamentally, the evolution of $\mathrm{CF}$ care can be attributed to establishing a network of European CF centres [4-6]. It is well documented that the management of $\mathrm{CF}$ in paediatric and adult cystic fibrosis centres results in better clinical outcomes [7]. Improvement in nutritional status (BMI), higher forced expiratory volume in one second (FEV1), and better chest X-ray scores were observed in patients who had received continuous care from $\mathrm{CF}$ centres compared to those who had received care in centres that did not specialise in CF [8].

The all-important framework for CF centres is central to ECFS standards of care, providing an endorsement of the model of care one should aspire to. An infrastructure concerning inpatient and outpatient clinics, sufficient capacity to prevent cross infection, and specialist equipment are all prerequisites to provide complex diagnostic management and treatment $[4,5]$.

The role of the multidisciplinary team is of paramount importance. The multidisciplinary team consists of $\mathrm{CF}$ care consultants, clinical nurse specialists, physiotherapists, dieticians, clinical psychologists, microbiologists, pharmacists, social workers, clinical geneticists, and allied healthcare professionals, all of whom subscribe to the notion of Continuing Professional Development (CPD) and play a vital role in the day-to-day operations of specialised CF centres [4].

\section{CYSTIC FIBROSIS POPULATION IN POLAND - CURRENT STATUS}

Contrary to ECFS standards, until recently there were no medical centres in Poland dedicated to $\mathrm{CF}$ care, despite a CF population of approximately 2000 , of whom an estimated $1 / 3$ are adults. However, in the absence of a formal $\mathrm{CF}$ registry programme, we suspect that there are many more CF sufferers yet to be correctly diagnosed. Our National Newborn Screening Programme (NBS) has been operational since 2009; however, the pilot study commenced in 1999. Based on data provided by our NBS programme, we estimate the prevalence of $\mathrm{CF}$ to be $1: 4394$ to $1: 5000$ $[9,10]$. In other words, there are 80 new diagnoses every year. The most common mutation is delF508 (62.4\%), the average patient age is approximately 16.2 years, and the median age at death is approximately 26.3 years.

The Institute of Mother and Child (our previous CF centre) is one of the largest paediatric CF centres in Poland. The institute was established in 1948 and has the status of a national research unit accredited by the Ministry of Health. Our paediatric CF centre consists of a paediatric department and an outpatient cystic fibrosis clinic. We have taken care of 400 patients less than 18 years old and receive approximately 20 new diagnoses every year.

Due to an increasing number of patients and a very limited capacity, our premises fell short of ECFS standards of care guidelines; consequently, the decision was made to build a new CF centre. This facility was the first state-of-the-art centre of its kind in Poland. Notwithstanding the lack of funding for $\mathrm{CF}$ care, raising awareness of CF care with a view to securing a commitment to appropriate funding was a challenge worth realising in the quest to deliver a model of care in accordance with ECFS recommendations.

Most of our team made the move to the new facility; however, it was widely acknowledged that much-needed reinforcement (e.g. recruitment of nurses) would be required to deliver best practice care. Part of our planning during the move included sharing information with an experienced CF centre based in Dresden, Germany. We used this experience to garner as much knowledge as possible by engaging in theoretical based training as well as in workshops in a clinical setting.

We hypothesised that training MDT personnel in ECFS standards of care would translate into increased levels of comfort among personnel in diagnosing and treating this chronic disease. The primary objective of this study was to assess the change in comfort levels with CF care among MDT personnel who participated in CF-specific training, using pre- and post-course questionnaires. To better understand the status quo, questionnaires were distributed among personnel. The intent was to ascertain CF care education levels and to gauge confidence levels in administering care. We also evaluated if there was an appetite for receiving additional education and what type of education would be fitting for this purpose.

\section{MATERIAL AND METHODS}

A qualitative needs assessment was performed with MDT members at the $\mathrm{CF}$ centre in the Institute of Mother and Child in order to identify desired CF care knowledge and practical skills. Heads of the paediatric CF centres from Warsaw and Dresden consulted to create CF-specific care training. This process was also attended by the coordinator of one of the Polish patient organisations. Based on the input by these authorities, a CF-specific care curriculum consisting of eighteen 60-minute sessions and practical activities was developed (Table 1). Sessions covered a broad range of $\mathrm{CF}$ care topics relevant to all stages of disease.

Training of the CF MDT from Warsaw took place during a visit in the CF Centre in Dresden. Head of the paediatric CF centre from Warsaw served as the course director and recruited session leaders from Polish and German CF experts. The director of the University Cystic Fibrosis Centre from Dresden was among them. Cystic fibrosis authorities led several of the sessions, including organisation of $\mathrm{CF}$ centre, diagnosis with emphasis on the role of newborn screening, and multidisciplinary aspects of treatment in CF at every stage of disease. There were sessions on issues of patient care at the end of life, discussing management of patients led towards lung transplants and those requiring palliative care. There was an 
TABLE 1. Cystic fibrosis - specific care curriculum sessions

\begin{tabular}{|l|}
\hline Session topics \\
\hline 1. Organisation of CF Centre \\
\hline 2. Diagnosis of CF \\
\hline 3. Newborn screening in CF \\
\hline 4. Introduction to care of CF patients \\
\hline 5. Nutritional management in CF \\
\hline 6. Physiotherapy in CF \\
\hline 7. Cross-infections in CF \\
\hline 8. Treatment of bronchopulmonary disease in CF \\
\hline 9. Lung transplantation in CF \\
\hline 10. End of life and palliative care \\
\hline 11. Transition from paediatric to adult care \\
\hline 12. Psychological problems in CF \\
\hline 13. Social support of Polish CF patients \\
\hline 14. The activities of CF patients organisation in Poland \\
\hline 15. History and organisation of CF Centre in Dresden \\
\hline 16. Characteristics of German CF population \\
\hline 17. Practical training in CF Department \\
\hline 18. Practical training in CF Outpatient Clinic \\
\hline
\end{tabular}

TABLE 2. Cystic fibrosis care team demographics $(n=26)$

\begin{tabular}{|l|c|}
\hline Discipline & $n(\%)$ \\
\hline Respiratory paediatrician/pulmonologist & $8(30.8)$ \\
Clinical nurses & $12(46.1)$ \\
Specialist dietitian & $2(7.7)$ \\
Clinical psychologist & $1(3.8)$ \\
Specialist physiotherapist & $1(3.8)$ \\
Social worker, project coordinator & $1(3.8)$ \\
Hospital support & $1(3.8)$ \\
All & $26(100)$ \\
\hline Patients served & \\
\hline Children & $19(73)$ \\
Adults & $3(11.5)$ \\
Children and adults & $4(15.3)$ \\
\hline Gender & \\
\hline Female & $23(88.46)$ \\
Male & $3(11.5)$ \\
\hline
\end{tabular}

opportunity to discuss the aspects and moral dilemmas associated with caring for patients and their families at every stage of the disease during the psychological session. During the training, sessions were also held on the support and sanitary assistance to patients and patient organisations. The CF Centre in Dresden held sessions on the history and organisation of the centre and the local characteristics of the CF population in Germany. Trainees took part in workshops in the Department and Outpatient Clinic, where in a practical way, the centre, facilities for diagnosis and monitoring of the disease in different laboratories (e.g. lung function tests, endoscopy), and rules for preventing cross-infection were discussed.

\section{TRAINING EVALUATION}

A single-group pre- and post-test design was used to assess the effectiveness of the training. A 37-question anonymous survey (Appendix) was created for members of CF MDT to assess their own comfort with the targeted CF care. The survey covered a core group of skills relevant to all team members, regardless of discipline. The first part of the survey included general questions $(n=11)$ on the position, the nature and duration of work, as well as training for CF care. The main part of the survey (26 items) assessed comfort level in three domains: involvement in CF care (6 items), knowledge of CF patients management (10 items), and practical skills (10 items), using a five-point Likert scale (i.e. 1 = very uncomfortable, $2=$ comfortable, 3 = neutral, $4=$ comfortable, $5=$ very comfortable). Pre- and post-course participants completed the same 37-question self-assessment survey.

\section{STATISTICAL ANALYSES}

The analysis was performed using Statistica 12 software. First, the verification of the normal distribution of results in the examined sections was performed by the Shapiro-Wilk normality test in order to select appropriate comparative tests. For comparison of time results for which both distributions did not differ significantly from normal, Student's t-test was used for dependent tests; otherwise, the Wilcoxon pair-order test was used. For comparisons between the two groups, the t-test for independent samples was used for normal distribution and, in the absence of normality, the Mann-Whitney U test was used. A significance level of 0.05 was adopted.

The change in self-assessed comfort level over all 26 items in the survey was the primary endpoint analysis. The changes in each of three domains: involvement in CF care (6 items), knowledge of CF patient management (10 items), and practical skills in CF care (10 items), were the secondary endpoints. The significance of the differences between the pre- and post-test results for the overall results and the three domains was also compared across the entire group as well as between old and new employees.

\section{RESULTS}

\section{DEMOGRAPHICS}

Twenty-six MDT members including eight respiratory paediatricians/pulmonologists, 12 clinical nurses, one specialist physiotherapist, two specialist dietitians, one clinical psychologist, one project coordinator, and one hospital support staff member participated in the training (Table 2). The majority of the care team (12) had more than 15 years of experience in their discipline (eight nurses, three physicians, and one dietitian), four had 10-15 years of work experience (two physicians, one 
dietitian, and one psychologist), and eight had 5-10 years of work experience (four nurses, two physicians, one social worker, and one hospital support staff member). The least experienced members of the care team included one physiotherapist and one doctor, a resident (0-5 years).

The majority of trainees (15-57\%) had experience in CF care, and 11 (42\%) were new workers. The new workers included clinical nurses and one hospital support staff member. Three physicians and one nurse had more than 15 years of experience in CF care. Two dietitians, one psychologist, and one nurse had been working on the CF team for 10-15 years, and one physician and coordinator had 5-10 years of experience. The rest of the group (four physicians and physiotherapists) had been on our team for 0-5 years. Three nurses worked in an adult-only setting, 19 members of the MDT worked in paediatrics, and four members (two nurses, one physiotherapist, and one coordinator) worked in both adult and paediatric settings.

\section{THE ROLE OF THE CF TEAM}

Respondents were asked before and after training to report their understanding of their role in the CF MDT. Most respondents who had experience in CF care reported that they "fully" understood their role (80\% of "old workers", corresponding to $46.1 \%$ of all) or had an "average" understanding of their role $(20 \%$ and $26.9 \%$ respectively). We observed a low level of reported understanding among new workers, with the following responses: "none", $9 \%$ (3.9\% of all) and "minimal", $36.3 \%$ (15.4\% of all). After training and meetings with the CF team from Warsaw and Dresden, all participants understood their role on the CF MDT. Awareness of their role on the team increased to "full" (76.9\% of all participants) and "average" (15.4 of all). This increase was observed primarily in the new employees group (45.4\% and 36.4\%, respectively).

We asked the CF healthcare providers if they felt adequately prepared to work as a CF MDT member. Before the training, all of the "old workers" felt "full" or "average" in terms of preparation, but in the new workers group $18 \%$ felt that they had no preparation, "none", or were "minimally" prepared. After theoretical and practical course preparedness to provide CF care, this parameter improved, especially in new members, to preparedness levels of "full" (36.4\%), "average" (45.4\%), and "somewhat" (18.2\%).

\section{CF TEAM MEMBER EDUCATION IN CF CARE}

We surveyed the total number of CF education hours that practitioners had received either in CF centre organisation and working rules or in CF patient care. All physicians, dietitians, psychologists, physiotherapists, the project manager, and three nurses who had previously worked with CF patients had received more than 20 hours of education in a CF centre organisation and specific CF care.
Most of the new employees did not have any training or only a very brief (10 hours) training on cystic fibrosis.

\section{CF TEAM MEMBER EDUCATION PREFERENCES}

The majority of CF healthcare providers received their knowledge about work and CF centre organisation from conferences (69.2\%), medical press publications (65.4\%), and the Internet (53.8\%). Only $26.9 \%$ had received relevant education in a medical school or at university. Similarly, the main sources of knowledge regarding CF patient care were conferences (80.6\%), publications (76.9\%), web-based education (73\%), and training at an institution (61.5\%). Only $30.7 \%$ had CF care education at college or university. The majority (76.9\%) of CF healthcare providers preferred education specific to CF delivered during conferences and tutorials at the workplace (73\%).

\section{SELF-ASSESSMENT LEVEL IN THREE DOMAINS}

There was a statistically significant difference in the questionnaire results before and after training both in the overall response $(p=0.000)$ as well as for the three categories (involvement $[p=0.000]$, knowledge $[p=0.000]$, and skills $[p=0.000])$. The average overall pre-training score was $86.6 \pm 26.8$ (SD), which increased to $112.1 \pm 15.4$ (SD) after training (Fig. 1). The average change in the involvement category before the training was $23.7 \pm 5.8$ (SD) vs. $28.0 \pm 2.4$ (SD) after training. The average change in the knowledge category prior to training was $33.3 \pm 10.4$ (SD) vs. $42.7 \pm 7.3$ (SD) after training. The average change of skill category before training was $29.6 \pm 11.74$ (SD) vs.

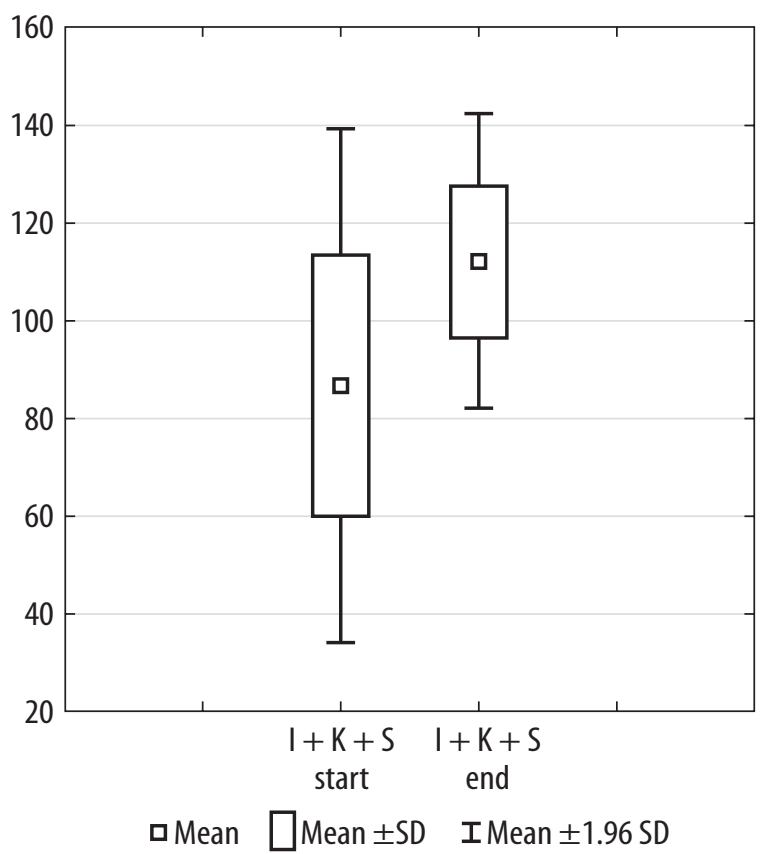

FIGURE 1. Significant differences in the questionnaire before and after training: the total score in all categories (involvement -I, knowledge $-K$, and skills $-S$ ) across all employees 
TABLE 3. Significance of questionnaire differences before (start) and after (end) training in general and for the three categories (involvement - I, knowledge $-K$, and skills $-S$ ) among all employees

\begin{tabular}{|l|c|c|c|c|c|c|c|c|}
\hline Dependent samples t-test & Mean & SD & $n$ & Difference & SD difference & $t$ & $d f$ & $p$ value \\
\hline I+ K + S start & 86.6 & 26.8 & & & & & & \\
\hline I+ K+ S end & 112.1 & 15.4 & 26 & -25.5 & 14.3 & -9.1 & 25 & 0.000 \\
\hline Involvement start & 23.7 & 5.8 & & & & & & \\
\hline Involvement end & 28.0 & 2.4 & 26 & -4.3 & 4.1 & -5.4 & 25 & 0.000 \\
\hline Knowledge start & 33.3 & 10.4 & & & & & & \\
\hline Knowledge end & 42.7 & 7.3 & 26 & -9.5 & 4.9 & -9.9 & 25 & 0.000 \\
\hline Skills start & 29.6 & 11.7 & & & & & & \\
\hline Skills end & 41.3 & 6.8 & 26 & -11.7 & 6.7 & -9.0 & 25 & 0.000 \\
\hline
\end{tabular}

$t$ - result of independent samples $t$-test, $d f$ - degrees of freedom

TABLE 4. Descriptive statistics of the questionnaire results on changes in pre- and post-training performance among old and new employees (categories: involvement - I, K, knowledge; and S: skills).

\begin{tabular}{|c|c|c|c|c|c|c|c|c|c|}
\hline Descriptive statistics & Status & $N$ & Mean & Median & Minimum & Maximum & $\begin{array}{c}\text { Lower } \\
\text { quartile }\end{array}$ & $\begin{array}{c}\text { Upper } \\
\text { quartile }\end{array}$ & SD \\
\hline$I+K+S$ change & old employee & 15 & 15.4 & 16 & 1 & 25 & 11 & 21 & 6.7 \\
\hline Involvement change & old employee & 15 & 1.7 & 2 & 0 & 5 & 0 & 2 & 1.8 \\
\hline Knowledge change & old employee & 15 & 6.5 & 7 & 0 & 11 & 4 & 9 & 3.2 \\
\hline Skills change & old employee & 15 & 7.1 & 7 & 0 & 11 & 5 & 10 & 3.1 \\
\hline$I+K+S$ change & new employee & 11 & 39.4 & 36 & 31 & 55 & 31 & 50 & 9.1 \\
\hline Involvement change & new employee & 11 & 7.9 & 7 & 4 & 18 & 6 & 8 & 3.8 \\
\hline Knowledge change & new employee & 11 & 13.5 & 13 & 8 & 19 & 10 & 17 & 3.8 \\
\hline Skills change & new employee & 11 & 18.0 & 18 & 10 & 27 & 15 & 20 & 4.7 \\
\hline
\end{tabular}

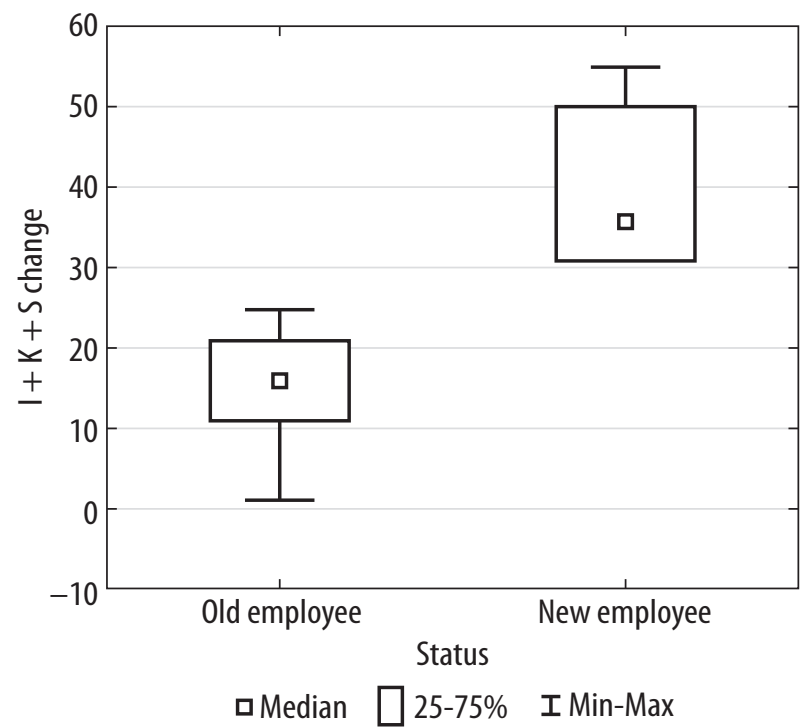

FIGURE 2. Significant differences in the changes in questionnaire results (involvement $-\mathrm{I}$, knowledge $-\mathrm{K}$, and skills $-\mathrm{S}$ ) between old and new employees before and after training

$41.3 \pm 6.8$ (SD) after training (Table 3 ). The significant differences for overall performance change and within the three domains between old and new employees were compared (Table 4). There were statistically significant differences in the changes in performance between the old and new performers for the results of all categories combined ( $p=0.000)$ (Fig. 2).
The median change in pre- and post-training results $(\mathrm{I}+\mathrm{K}+\mathrm{S})$ among old workers was 16 , while the median change among new workers was 36 . The median change in the involvement category for old workers was 2 vs. 7 among new workers. There were statistically significant differences between changes in the knowledge category results $(p=0.000)$ and skills $(p=0.000)$. The average improvement among old employees in the knowledge category was $6.5 \pm 3.2$ (SD), compared to the average improvement of $13.0 \pm 3.8$ (SD) in the new employees group. The average improvement among old workers in the skills category was $7.1 \pm 3.1$ (SD), compared to the average improvement of $18.0 \pm 4.7$ (SD) in the new employees group.

\section{DISCUSSION}

Cystic fibrosis care worldwide has improved in line with ECFS standards. The role of CF centres in achieving optimal outcomes is not in doubt [4]. The multidisciplinary team has a fundamental role to play; therefore, the team should receive strong support by way of continued professional development [11]. The objective of this study was to assess the change in comfort levels after the delivery of CF-specific training and to gauge the impact the training had on the core skills necessary to deliver optimal outcomes.

Our paediatric CF centre in Warsaw reached a landmark upon completion of our new state-of-the-art CF 
centre (opened January 2017) situated on the outskirts of Warsaw. The new building meets ECFS guidelines, with a "rooming in" facility incorporated in its outpatient clinic, the first of its kind in Poland. There is also a modern pulmonary function test laboratory with new equipment, including multiple breath washout (MBW), oscillometry, and plethysmography devices. In the future, the facility will include a Biomarkers Laboratory.

The vision of this project was to create a modern CF centre and implement the guidelines and standards set out by the ECFS, which are central to MDT personnel delivering best practice care. Continuing professional development is crucial to upholding CF standards of care. A recent study that evaluated the knowledge and preparedness of a CF team in delivering CF palliative care confirmed the dire need for training $[12,13]$. A fair number of key CF care workers did not understand their role and felt inadequately prepared to deliver best practices in palliative care. As our study confirms, CF-specific training was well received by our MDT. Furthermore, CF training significantly improved self-assessed comfort levels along with the core skills necessary to deliver optimal outcomes.

The group participating in our survey had varying levels of experience working in a CF team, with both experienced MTD personnel and new employees. Most of our team from The Institute of Mother and Child started working at our new centre. However, we had to supplement our workforce by hiring new workers, especially nurses. There was an overriding need to ensure the team was prepared for work; thus, appropriate training was arranged.

Training was well received by participants; all agreed that the CF-specific agenda was very helpful in furthering their knowledge and skill-base in CF patient care.

After completing the training, $\mathrm{CF}$ care providers reported significantly higher levels of comfort than they had before. Among the 26 course participants, there were significant changes in mean comfort levels in the three domains tested. The theoretical and practical content of the course increased awareness, particularly among new employees. The results of the survey reinforced the need for additional CF training. The survey also highlighted a need to constantly challenge and keep abreast of educational developments.

Our trip to Dresden was a testament to collaboration and proved to be an unparalleled success. The effectiveness of working together, sharing information, and disseminating best practices is an innovative way of working in healthcare and a template for other institutes to replicate going forward.

\section{CONCLUSIONS}

The decision to organise exit training for an entire multidisciplinary team was innovative and thought-pro- voking, not least because of the camaraderie it fostered. Collaboration as a template marked a shift away from working in isolation (healthcare institutions) to working together as a team to deliver better outcomes and improve service delivery. Ultimately, a forward-thinking approach to education has increased comfort levels and raised awareness in managing this complex disease through a coordinated, multifaceted approach and a commitment to continuing professional development, which certainly bodes well for the future delivery of CF care at the national and international levels.

\section{ACKNOWLEDGEMENTS}

We are most grateful to Jutta Hammermann $\mathrm{PhD}$ and CF professionals from the Paediatric Department, University Hospital of Dresden, Germany.

\section{DISCLOSURE}

The authors declare no conflict of interest.

\section{REFERENCES}

1. Castellani C, Conway S, Smyth AR, et al. Editioral Standards of Care for Cystic Fibrosis ten years later. J Cyst Fibros 2014; 13: 1-2.

2. Smyth AR, Bell SC, Bojcin S, et al. European Cystic Fibrosis Society Standards of Care: Best Practice guidelines. J Cyst Fibros 2014; 13 (Suppl. 1): 23-42.

3. Cohen-Cymberknoh M, Shoseyov D, Kerem E. Standards of care for patients with cystic fibrosis. Eur Respir Monogr 2014: 64: 246-261.

4. Conway S, Balfour-Lyn IM, De Rijcke K, et al. European Cystic Fibrosis Society Standards of Care: Framework for the Cystic Fibrosis Centre. J Cyst Fibros 2014; 13: 3-22.

5. Colombo C, Litlewood J. The implementation of standards of care in Europe: State of art. J Cys Fibros 2011; 10 (Suppl.): 7-15

6. Stern M, Bertrand DP, Bignamini E, et al. European Cystic Fibrosis Society Standards of Care: Quality Management in cystic fibrosis. J Cys Fibros 2014; 13: 43-59

7. Johnson C, Butler SM, Konstan MW, et al. Factors influencing outcomes in cystic fibrosis. A center-based analysis. Chest 2003; 123: 20-27.

8. Mahadeva R, Webb K, Westerbeek RC, et al. Clinical outcome in relation to care in Centres specialising in cystic fibrosis: cross sectional study. BMJ 1998; 316: 1771-1775.

9. Sobczyńska-Tomaszewska A, Ołtarzewski M, Czerska K, et al. Newborn screening for cystic fibrosis: Polish 4 years' experience with CFTR sequencing strategy. Eur J Hum Genet 2013; 21: 391-396.

10. Farrell PM. The prevalence of cystic fibrosis in the European Union. J Cyst Fibros 2008; 7: 450-453.

11. Cofta S, Sands D, Skorupa W, et al. Standardy opieki Europejskiego Towarzystwa Mukowiscydozy: wytyczne i najlepsze praktyki. Pediatr Pol 2016; 91 (Suppl. 1): S54-58.

12. Goggin J, Cohen RI. CF healthcare workers feel unprepared in providing suitable end of life care and desire more education: Results of a nationwide survey. J Cyst Fibros 2016; 15: 85-89.

13. Linnemann RW, O’Malley PJ, Friedman D, et al. Development and evaluation of a palliative care curriculum for cystic fibrosis healthcare providers. J Cys Fibros 2016; 15: 90-95. 
Appendix

\section{Survey questionnaire}

Contents:

I. General questions (general part) - 11

II. Involvement - 6

III. Knowledge - 10

IV. Practical skills - 10

\section{General questions (general part)}

1. What is your role in Cystic Fibrosis Multidisciplinary Team (CF MDT)?

a. Medical doctor/consultant

b. Nurse

c. Dietician

d. Psychologist

e. Physiotherapist

f. Social worker

g. Other

2. What is your working experience as a medical professional?
a. $0-5$ years
b. 5 - 10 years
c. $10-15$ years
d. Over 15 years

3. What is your working experience as a CF MDT member?
a. I have no working experience
b. Less than 5 years
c. 5 - 10 years
d. $10-15$ years
e. Over 15 years

4. What is your current working place?
a. Clinical ward
b. Outpatient clinic
c. Both: clinical ward and outpatient clinic
d. Other:

5. What patients have you been working with so far in your medical career?
a. Children
b. Adults
a. Both: children and adult patients

6. How much training regarding CF Medical Centre organisation and working rules have you already received?
a. I have not received any training so far
b. 1-10 hours
c. 10-20 hours
d. 20-30 hours
e. Over 40 hours

7. What are the sources of your knowledge regarding the CF Medical Centre functioning and organisation? a. Medical school or medical university

b. Conferences c. Tutorials at my working place

d. Internet

e. Medical press publications

f. Other sources

g. I am a new worker

8. How much training regarding the $\mathrm{CF}$ patients care have you already received?
a. I have not received any training (I am a new worker)
b. 1-10 hours
c. 10-20 hours
d. 20-30 hours
e. Over 40 hours

9. What are the sources of your knowledge regarding CF patient care?
a. Medical school or medical university
b. Conferences
c. Tutorials at my workplace
d. Internet
e. Medical press publications
f. Other sources

10. Would you like to participate in further training/ tutorials regarding CF patient care/management?
a. Yes, very much
b. Yes, a little bit/moderately
c. Not too much
d. Not at all

11. What form of training do you prefer?
a. Conferences
b. Tutorials at my workplace
c. Internet
d. Medical press publications
e. Other

\section{Involvement and preparation to work as a member of a CF MDT}

12. What has been your involvement in CF patient care so far?
a. Major
b. Moderate
c. Neutral
d. Minor
e. I was not involved in CF patient care at all/I am a new worker

13. What input into CF patient care in CF MDT would you like to have?
a. Major
b. Moderate
c. Neutral
d. Minor
e. I do not want to have any input at all 
14. What is your understanding of your role as a CF MDT member?
a. Full
b. Average
c. Neutral
d. Minimal
e. I do not understand my role as a CF MDT mem- ber at all

15. Do you find yourself well prepared to work as a CF MDT member?

a. Yes, I am fully prepared to work as a CF MDT member

b. I feel moderately prepared to work as a CF MDT member

c. Neutral

d. I feel minimally prepared to work as a CF MDT member

e. I feel not prepared at all to work as a CF MDT member

16. Are you afraid of/apprehensive about working with CF patients?

a. Yes, I am very afraid of/apprehensive about working with CF patients

b. Yes, I am moderately afraid of/apprehensive about working with CF patients

c. Neutral

d. Yes, I am little bit afraid of/apprehensive about working with CF patients

e. No, I am not afraid of/apprehensive at all about working with CF patients

17. Do you find yourself well prepared to work in the CF Medical Centre?
a. I am very well prepared
b. I am moderately prepared
c. Neutral
d. I am underprepared
e. I am not prepared at all

\section{Questions regarding knowledge about CF}

How do you assess your knowledge regarding the following topics of CF patient management?

18. Organisation of the CF Medical Centre:
a. Very good
b. Good
c. Neutral
d. Adequate
e. Inadequate

19. CF diagnosis:
a. Very good
b. Good
c. Neutral
d. Adequate
e. Inadequate

20. CF patient management:
a. Very good
b. Good

c. Neutral

d. Adequate

e. Inadequate

21. Dietetic approach in CF patients:
a. Very good
b. Good
c. Neutral
d. Adequate
e. Inadequate

22. Physiotherapy in CF patients:
a. Very good
b. Good
c. Neutral
d. Adequate
e. Inadequate

23. Cross-infections in CF patients:
a. Very good
b. Good
c. Neutral
d. Adequate
e. Inadequate

24. Bronchopulmonary disease management:
a. Very good
b. Good
c. Neutral
d. Adequate
e. Inadequate

25. Lung transplantation in CF patients:
a. Very good
b. Good
c. Neutral
d. Adequate
e. Inadequate

26. Psychological problems in CF patients:
a. Very good
b. Good
c. Neutral
d. Adequate
e. Inadequate

27. Organisations supporting CF patients:
a. Very good
b. Good
c. Neutral
d. Adequate
e. Inadequate

\section{Questions regarding practical skills in CF care}

Overall, how comfortable do you feel about:

28. Providing support, advice, and education to new diagnosis patients and families:
a. Very comfortable
b. Comfortable
c. Neutral
d. Uncomfortable
e. Very uncomfortable 
29. Discussing a patient's prognosis with patients and family members:
a. Very comfortable
b. Comfortable
c. Neutral
d. Uncomfortable
e. Very uncomfortable

30. Optimising patient adherence to prescribed therapies:
a. Very comfortable
b. Comfortable
c. Neutral
d. Uncomfortable
e. Very uncomfortable

31. Managing social and practical concerns of patients living with CF:
a. Very comfortable
b. Comfortable
c. Neutral
d. Uncomfortable
e. Very uncomfortable

32. Discussing lung transplant candidacy with patients and family members:

a. Very comfortable

b. Comfortable

c. Neutral

d. Uncomfortable

e. Very uncomfortable

33. Initiating general conversation about end of life with patients and family members:
a. Very comfortable
b. Comfortable
c. Neutral
d. Uncomfortable
e. Very uncomfortable

34. Support and education during the transition from paediatric to adult care:
a. Very comfortable
b. Comfortable
c. Neutral
d. Uncomfortable
e. Very uncomfortable

35. Providing support and education for nutrition management:

a. Very comfortable

b. Comfortable

c. Neutral

d. Uncomfortable

e. Very uncomfortable

36. Providing support and education for inhalation therapy:
a. Very comfortable
b. Comfortable
c. Neutral
d. Uncomfortable
e. Very uncomfortable

37. Providing support and education for prevention of cross-infection:
a. Very comfortable
b. Comfortable
c. Neutral
d. Uncomfortable
e. Very uncomfortable 